\title{
Societal Analysis of Water Tourism Based On the Sustainable Development Goals: A Conceptual Review and Content Analysis
}

\author{
Javaneh Mehran $^{1}$, Alireza Farahat ${ }^{2}$ \\ ${ }^{1}$ Faculty of Tourism, Onbeş Kasım Kıbrıs University, Lefkoşa, KKTC, Turkey \\ ${ }^{2}$ University Nova of Lisboa
}

\begin{abstract}
:
In the context of social tourism, water become an exceptional topic for its distinctively multiscale social and cultural perspectives. Water tourism as both transportation and leisure activity reported to have complex socio-cultural and environmental impact at different level of society. However, water and coastal recreations remains as one of noticeable context in tourism studies, there are still some nexus vague concerning the role of water tourism as a potential contributory factor to the leisure domain of life, psychological resources and social well-being. The primary purpose of this study is to analysing the impact of water tourism to advance the understanding of the progress in this field. Furthermore, it aims to discover trends and mentalities of waterbased landscapes and activities in todays' society in order to improve the quality of life for both tourists and local communities. This study uses conceptual review and content analysis, obtaining results that confirm the strategic role of water tourism at micro, meso and macro level, which covers both a supply- and demand-side perspectives.

This study intends to address the following research questions: To what extent, hydrological leisure resources can encourage the rise of a new cultural attitude regarding water-based experiences or have the potential to spread an awareness about the responsible use of this social asset? How the advancement of water recreation activities would influence the wellbeing and life quality of tourist and local communities? Under what circumstances the rise on a new understanding of water-based experiences would have positive socioeconomic, cultural and environmental impulse for the conservation of these areas at global scale? What marketing strategies could target the most loyal segment in this aspect of tourism?

The implication of this conceptual review at different level of society would generate new sensitivity about the scientific and practical action to importance of water tourism and its significance in socioeconomic development and environmental sustainability.
\end{abstract}

Key words: water tourism, social wellbeing, societal analysis, sustainable development goals 